\title{
NEW METHODOLOGY TO ESTIMATE THE FATIGUE BEHAVIOR OF BITUMINOUS MIXTURES USING A STRAIN SWEEP TEST
}

Ramon Botella

Universitat Politècnica de Catalunya - BarcelonaTech

Jordi Girona 1-3, B1 215, 08034 Barcelona, Spain

+34 934017085

ramon.botella@upc.edu

Félix E. Pérez-Jiménez

Universitat Politècnica de Catalunya - BarcelonaTech Jordi Girona 1-3, B1 201, 08034 Barcelona, Spain

Rodrigo Miro

Universitat Politècnica de Catalunya - BarcelonaTech Jordi Girona 1-3, B1 201, 08034 Barcelona, Spain

Adriana H. Martínez

Universitat Politècnica de Catalunya - BarcelonaTech Jordi Girona 1-3, B1 216, 08034 Barcelona, Spain 


\section{Abstract}

Fatigue cracking of bituminous mixtures is closely related to the loss of ductility produced by the stiffening of the bituminous binder. The main two factors that cause the asphalt binder to lose its ductility are aging and exposure to low temperatures. However, most of the tests designed to evaluate the fatigue behavior of bituminous mixtures are very time consuming, and make unpractical those studies that try to evaluate the influence of many variables. In this research project a strain sweep test was used to analyze the influence of aging, test temperature and bituminous binder type on the fatigue behavior of a continuously graded mixture. As expected, the mixture with SBS polymer modified binder retained more ductility at low temperatures, while the mixture with crumb rubber modified binder had the highest stiffness modulus. All mixtures exhibited the worst fatigue behavior at low temperatures and aging was equivalent to testing an unaged mixture at a lower temperature. The main result of this paper was the implementation of a new methodology to estimate the fatigue law of the material using a strain sweep test, which allowed this fatigue analysis to be carried out in nearly 10 times less testing time than that required by the procedure described in the EN 12697-24 standard.

Keywords: bituminous mixtures, asphalt binder, fatigue, strain sweep test, aging 


\section{Introduction}

Cracking of asphalt pavements due to cyclic loading is a matter of utmost importance in the pavement engineering field. This phenomenon is closely related to the embrittlement the mixture suffers due to exposure to low temperatures and/or aging caused by weather agents. Oxidation produces a chemical change of the asphalt binder that increases its stiffness and makes the mixture more brittle and susceptible to fatigue and thermal cracking (Domke et al. 2000; Petersen et al. 1993; Chen and Huang et al. 2000; Al-Azri et al. 2006; Naskdar et al. 2013). Another factor that increases the asphalt binder stiffness is a reduction in temperature. There is some disagreement about the mechanism responsible for this phenomenon (Tabatabaee et al. 2012). A commonly accepted explanation of this phenomenon combines the effect of the reduction of the free volume between molecules (Struik 1978) and the formation of crystalline fractions, especially the wax contained in the asphalt binder (Planche et al. 1998; Claudy et al. 1992; Anderson and Marasteanu 1999; Lu et al. 2003).

Despite the importance of the in-service temperature and aging in the cracking resistance of the mixture under cyclic loading, these variables are rarely studied when designing a bituminous pavement. This is due to the amount of time required to evaluate this property. The European standard UNE-EN 12697-24 establishes a minimum of six cyclic tests at three different loading levels to estimate the fatigue law of the mixture, i.e. an exponential relationship between the strain or stress and the cycles to failure. The duration of each of these tests can range between 10 minutes and 3 days. One third of the specimens have to last over $10^{6}$ cycles, which implies at least 6 tests over 9 hours duration at $30 \mathrm{~Hz}$. A common laboratory can spend more than a week obtaining a fatigue law of a bituminous mixture. Therefore, studying the influence of different variables in just one type of mixture can involve months of testing, making the process very unpractical. 
As a consequence, several research teams have been looking for a way to reduce the time needed to characterize the fatigue behavior of bituminous materials either by developing new test procedures (Moreno-Navarro and Rubio-Gamez 2016; Gonzalez-Torre et al. 2015) or implementing computer simulation programs (Ma et al. 2016; Hu et al. 2016), that would make it possible to study the influence of different variables in the fatigue cracking process. Special attention should be paid to the work carried out to develop the Viscoelastic Continuum Damage Model (VECD) (Park et al. 1996), since most of the publications in this field follow this line of research. This theory is based on defining three key relationships. First the relationship between stresses and strains, then the law that governs the evolution of damage in the material and finally the dependency of the damage on the measurable variables that can be extracted from testing. Over the last 20 years this model has been developed to predict the behavior of mixtures under cyclic loading, and still today several authors are researching how to use and improve this methodology (Sabouri and Kim 2014; Park et al. 2014; Sadek et al. 2016).

Following the VECD approach, in 2010 Johnson developed (Johnson 2010; Hintz et al. 2011) a test method based on the Dynamic Shear Rehometer (DSR) that provided the number of cycles to failure at a given strain amplitude for bituminous binders using a strain sweep test that accelerated the accumulation of damage in the specimen, and applying the damage evolution law provided by the VECD theory.

Another approach has been proposed by some authors. The hypothesis is that the resistance to cracking exhibited by the material in monotonic tests should be related to the cracking behavior under cyclic loading. Such is the case of the approach proposed by Pérez-Jiménez et al. (Pérez-Jiménez et al. 2010; PérezJiménez et al. 2012). Using the direct tension fracture test Fenix, it was proven that a reasonably good correlation exists between the results obtained in flexural fatigue tests and those obtained from the fracture test. In this case, authors related the coefficients from the fatigue law obtained using the threepoint bending beam test (UNE EN 12697-24) with two parameters obtained in the Fenix test. 
Recently, following the same line of research, Na Chiangmai (2014), showed that a fairly good correlation exists between the released energy during cyclic testing and the fracture energy, both obtained using the Disk-shaped Compact Tension tests $(\mathrm{DC}(\mathrm{T}))$.

This paper presents a method to estimate the fatigue law of bituminous mixtures using a strain sweep test that reduces the testing time required from weeks to hours. The originality of this method lies in estimating the fatigue law of the material using two key strain amplitude values obtained in this test. The procedure is called EBADE (standing for the Spanish words for strain sweep test) (Pérez-Jiménez et al. 2011) and it is based on a uniaxial cyclic test performed on a double-notched prismatic specimen. This quick procedure was employed to analyze the influence of binder type, aging and test temperature on the fatigue behavior of a semi-dense graded mixture.

The UNE EN 12697-24 standard requires 6 replicates to be tested at three strain amplitudes, a total of 18 replicates. These strain amplitudes should be chosen so the number of cycles to failure is around $10^{4}$ and $2 \cdot 10^{6}$ cycles. The results of each group of 6 replicates are averaged and 3 data points (strain, cycles) are obtained. These 3 points are then fitted to an expression described by equation 1 :

$$
\varepsilon=a \cdot N^{-b},
$$

where $\varepsilon$ is the strain amplitude, $N$ is the number of cycles to failure and $a$ and $b$ are the fitting coefficients.

Assuming three groups of tests of 50,000,300,000 and 1,000,000 cycles of duration are conducted, at $30 \mathrm{~Hz}$ as described by the standard, 75 hours of testing time are required to obtain the fatigue law of one mixture. Multiply that by three mixtures, three temperatures and two aging conditions, the result is 1,350 hours of testing time. However, an EBADE test takes less than 3 hours, which resulted in less than 162 hours of testing to conduct the same study, nearly a tenth of the testing time required by the four point bending beam fatigue test, as described in the UNE EN 12697-24 standard. 


\section{Materials and test methods}

\subsection{Materials}

Three different mixtures were manufactured, with three different asphalt binders and the same gradation. The binders were a conventional binder with a penetration grading at $25^{\circ} \mathrm{C}$ of 50 to $700.1 \mathrm{~mm}$, from now on $50 / 70$, a crumb rubber modified binder, BC 35/50 and an SBS polymer modified binder PMB 45/80-65. The characteristics of these three binders are summarized in table 1. 
Table 1. Characteristics of asphalt binders

\begin{tabular}{|c|c|c|c|c|c|}
\hline Property & Unit & Standard & $50 / 70$ & BC 35/50 & $\begin{array}{l}\text { PMB 45/80- } \\
65\end{array}$ \\
\hline Penetration & $0,1 \mathrm{~mm}$ & EN 1426 & 57 & 46 & 48 \\
\hline $\begin{array}{l}\text { Softening } \\
\text { point }\end{array}$ & ${ }^{\circ} \mathrm{C}$ & EN 1427 & 50.2 & 66 & 62 \\
\hline Pen. Index & & Annex A & -0.85 & 1.94 & 1.31 \\
\hline $\begin{array}{l}\text { Elastic } \\
\text { recovery @ } \\
25^{\circ} \mathrm{C}\end{array}$ & $\%$ & EN 13398 & No data & 61 & 86 \\
\hline $\begin{array}{l}\text { Fraass } \\
\text { breaking } \\
\text { point }\end{array}$ & ${ }^{\circ} \mathrm{C}$ & EN 12593 & No data & -11 & -17 \\
\hline \multicolumn{6}{|c|}{ Residue after RTFOT } \\
\hline $\begin{array}{l}\text { Mass } \\
\text { change }\end{array}$ & $\%$ & EN 12607-1 & 0.02 & 0.01 & 0.01 \\
\hline $\begin{array}{l}\text { Penetration } \\
\text { after RTFOT }\end{array}$ & $0,1 \mathrm{~mm}$ & EN 1426 & 35 & 36 & 40 \\
\hline $\begin{array}{l}\text { Retained } \\
\text { pen. @ } 25 \\
{ }^{\circ} \mathrm{C}\end{array}$ & $\%$ & EN 12607-1 & 61.4 & 78.3 & 83.3 \\
\hline $\begin{array}{l}\text { Softening } \\
\text { point after } \\
\text { RTFOT }\end{array}$ & ${ }^{\circ} \mathrm{C}$ & EN 1427 & 56.4 & 72 & 68.8 \\
\hline $\begin{array}{l}\text { Increasing } \\
\text { of softening } \\
\text { point R\&B }\end{array}$ & ${ }^{\circ} \mathrm{C}$ & EN 12607-1 & 6.4 & 6 & 6.8 \\
\hline
\end{tabular}

The gradation employed to fabricate the mixtures was a semi-dense AC mixture with an upper sieve size of $16 \mathrm{~mm}$ (AC16 Semi-dense), a $5.0 \%$ of binder content by mass of the aggregates and the target void content was $4.0 \%$. The specimens were prepared using the Marshall compactor with 75 blows per side, and then sawn to get the prismatic specimens required for the test. The mixtures manufactured using the conventional and polymer modified binder presented very similar densities, $0.12 \%$ difference in the average densities, while the mixture manufactured using the crumb-rubber modified binder showed an average density $1 \%$ lower. 
Table 2. AC16S gradation employed in the mixture fabrication.

\begin{tabular}{|l|l|}
\hline Sieve $(\mathrm{mm})$ & Percent passing (\%) \\
\hline 22 & 100 \\
\hline 16 & 95 \\
\hline 8 & 67.5 \\
\hline 4 & 41.5 \\
\hline 2 & 31 \\
\hline 0.5 & 16 \\
\hline 0.25 & 11 \\
\hline 0.063 & 5.25 \\
\hline
\end{tabular}

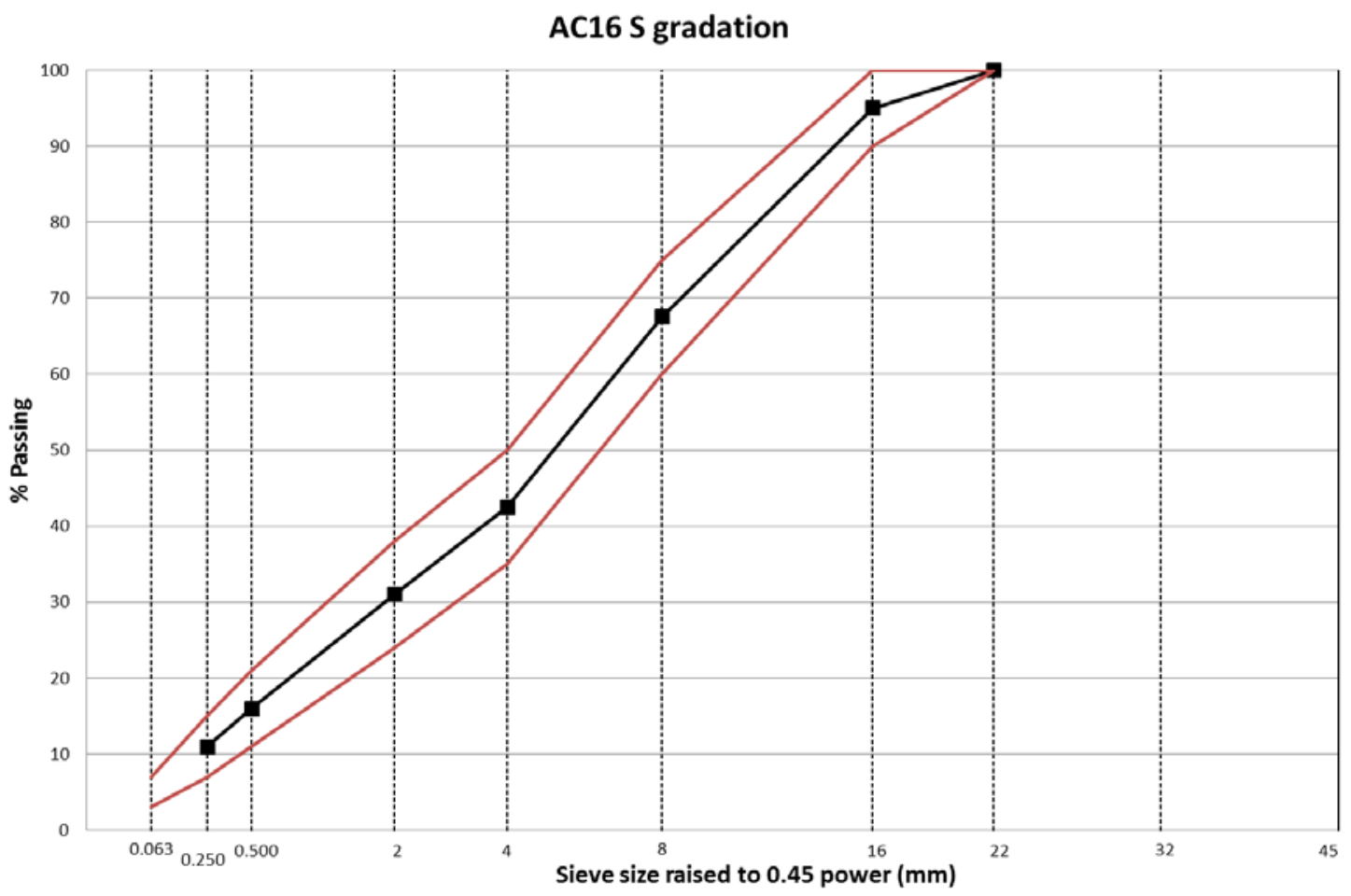

Figure 1. AC16 S gradation.

To simulate aging, the procedure designed by the RILEM ATB-TG5 group was employed (De la Roche et al. 2009). After mixing the aggregates with the binder, the mixtures were spread out in trays with a maximum height of $6 \mathrm{~cm}$ and placed in a forced air oven at $85^{\circ} \mathrm{C}$ for 7 days. Afterwards, the mixture was re-heated to manufacture cylindrical specimens using the Marshall compaction procedure. 


\subsection{EBADE test}

EBADE tests consist of a uniaxial tension-compression strain controlled test (Pérez-Jiménez et al. 2011; Pérez-Jiménez et al. 2015). The strain amplitude is controlled by one extensometer, and is increased with a single increment every 5,000 cycles. Each block of 5,000 cycles at the same strain amplitude is called a strain step. The test starts at 25 microstrains and the increment is also 25 microstrains. That means that the amplitude in the second step is $\mathbf{5 0}$ microstrains, in the third step 75 microstrains, and so on. The test is conducted at $10 \mathrm{~Hz}$. While the duration depends on the ductility of the mixture, it is normally under 3 hours, fewer than 100,000 cycles; however, at high temperatures and/or when testing modified binders, exceptionally, the test can last more than 150,000 cycles.

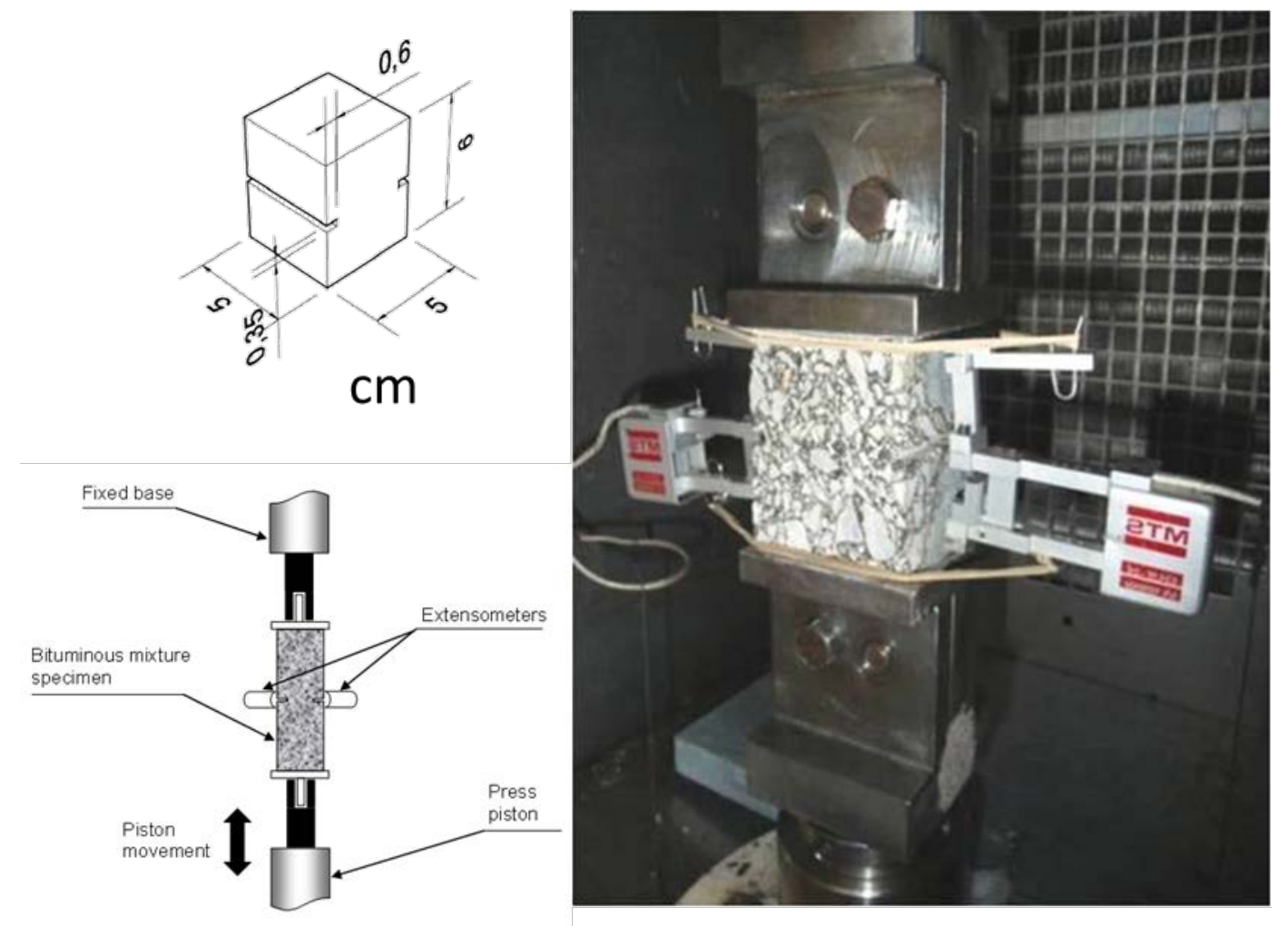

Figure 2. EBADE test configuration.

The specimens employed are prismatic of $5 \times 5 \times 6 \mathrm{~cm}^{3}$ with two $0.6 \mathrm{~cm}$ deep and $0.35 \mathrm{~cm}$ wide notches in two of the $6 \mathrm{~cm}$ tall faces, figure 2 . These specimens are cut from cylindrical samples and glued to steel plates specially designed to fit in an MTS hydraulic press. 
During the test the strain amplitude is controlled through one of the extensometers and the resulting load is recorded, for a whole cycle every 100 cycles. The load is divided by the cross-sectional area of the specimen, reduced because of the notches, to find the experimental stress, and from there the stress amplitude, the complex modulus, $\left|E^{\star}\right|$, and the dissipated energy density, DED, are calculated.

The test provides two main parameters that can be used to characterize the behavior of the material under cyclic loading:

- Norm of the initial complex modulus, $\left|\mathrm{E}^{*}\right| \mathrm{i}$ : The average of all complex modulus values recorded during the first 5,000 cycles performed at 25 microstrains amplitude, 50 values in total. At this strain level, the complex modulus does not change with the number of cycles. When comparing different variables, this complex modulus value has the advantage of having been obtained in the same conditions.

- Failure strain, $\varepsilon_{F}$ : The strain amplitude corresponding to the strain step at which the dissipated energy density drops below $50 \%$ of the maximum value reached during the test.

\subsection{No-Damage strain}

In this subsection, the procedure to obtain the No-Damage strain, $\varepsilon_{\mathrm{ND}}$, is defined and justified.

Due to the calculation process of both the $\left|\mathrm{E}^{\star}\right|$ and the $\mathrm{DED}$, the latter presents a more stable pattern throughout the test. This is caused by the fact that the area inside the stress-strain loop is less affected by small deviations in the load data than the slope defined by the maximum stress and strain in each cycle. Because of this, the criteria to calculate the $\varepsilon_{\mathrm{ND}}$ are based on the behavior of the DED within each strain amplitude step.

One way to measure the change in DED within each strain amplitude step is by calculating the slope of a linear regression between DED and the number of 
cycles every 5,000 cycles (the duration of each strain step). The two first strain steps in the EBADE test correspond to 25 and 50 microstrains respectively. The literature [20] states the endurance limit of asphalt mixtures at a strain twice or three times higher than this. It is safe to assume that during these two steps the mixtures tested at $10^{\circ} \mathrm{C}$ should behave linearly, and therefore, no change should be detected in DED. Computing the DED/cycles slope values in the first and second steps for all tests performed at $10^{\circ} \mathrm{C}$, it was found that the highest value was $2.0 \mathrm{E}-4 \mathrm{~J} / \mathrm{m}^{3}$. As shown in Figure 3, the increase in the DED/cycles slope with the strain amplitude could be fairly approximated by an exponential function. Taking that into account, and to provide a wide range of error in the measurement of the slope, the maximum slope value that means no change in DED was established as $1.0 \mathrm{E}-3 \mathrm{~J} / \mathrm{m}^{3}$.

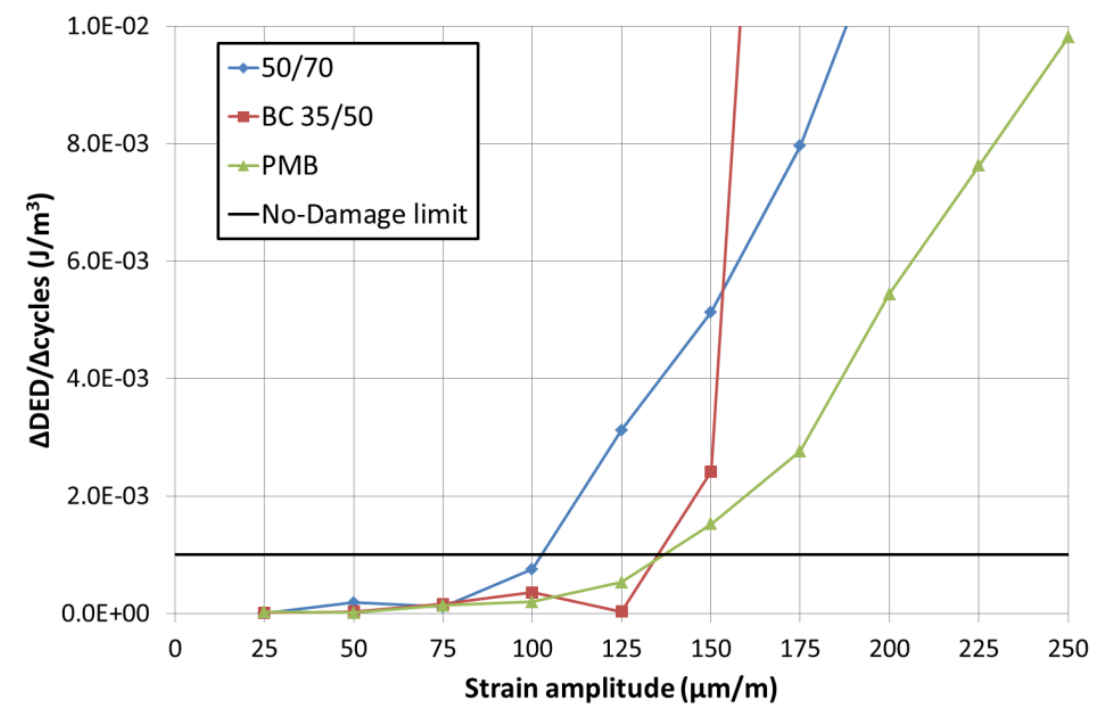

Figure 3. $\triangle \mathrm{DED} / \Delta$ cycles slope evolution with the strain amplitude in EBADE tests at $10^{\circ} \mathrm{C}$.

Therefore, slopes steeper than this value indicate the material is decreasing its $\left|E^{\star}\right|$ and DED. Figure 4 shows graphically how the change in the DED/cycles slope could be used to define the highest strain amplitude at which these properties of the material remain constant. 


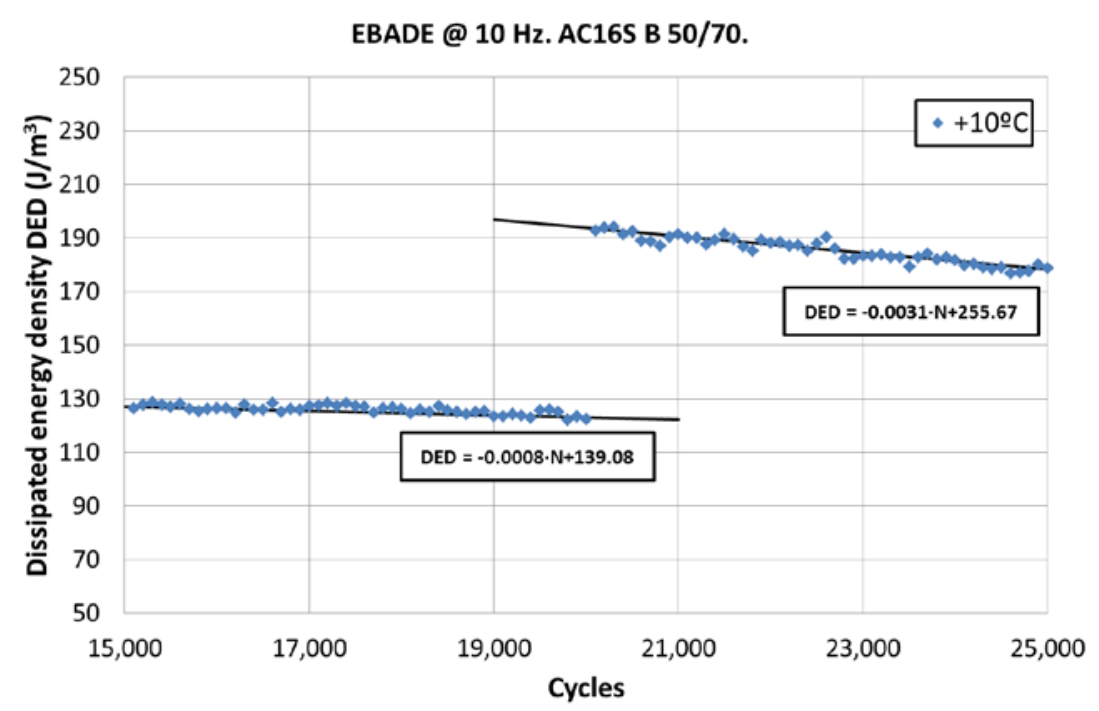

Figure 4. Graphical example of the DED/cycles slope change in EBADE tests.

Once the limit DED/cycles slope value is set, a systematic procedure is required to convert the slope into a strain amplitude value. In EBADE tests the strain amplitude varies by 25 microstrains every 5,000 cycles, starting at an initial strain amplitude of the same value. That means that the precision in strain amplitude is 12.5 microstrains. When it comes to finding the failure strain that precision could be enough; however, at low strain amplitudes, the relative precision is lower. For that reason, the $\varepsilon_{N D}$ values were calculated using linear interpolation to find the strain amplitude corresponding to a $1.0 \mathrm{E}-3 \mathrm{~J} / \mathrm{m}^{3}$ slope.

\subsection{Fatigue law estimation}

Considering the two strain related parameters that can be obtained from the EBADE test, a theoretical fatigue law can be sketched.

On the one hand, there is $\varepsilon_{F}$, which is related to a strain amplitude that will cause failure of the material in a relatively short number of cycles. In fact, when the test reaches this strain amplitude failure takes place in 5,000 cycles or fewer. Taking into account that by that time the specimen has undergone a significant number of cycles at lower strain amplitudes, it would be reasonable to state that at $\varepsilon_{\mathrm{F}}$ a conventional time sweep fatigue test would last around 10,000 cycles. Previous research has proved that this hypothesis is very close to the real data from the time sweep test (Pérez-Jiménez et al. 2013). 
On the other hand, the $\varepsilon_{\mathrm{ND}}$ fixes the highest strain amplitude the material can take without changing its properties with the number of cycles, and, by definition, at this strain level there is no measurable change in DED and, therefore, there is no measurable damage accumulation. As a consequence, at this strain amplitude the material could resist an infinite number of cycles. The domain in which the strain amplitude and the number of cycles to failure relate following a potential law is comprised approximately between 10,000 and 10 million cycles (Carpenter et al. 2003), above that number, the number of cycles to failure does not depend on the strain applied, as a matter of fact failure may not take place at all. Therefore, relating the strain amplitude at which there is no change in DED with a time sweep test that would last for, at least, 10 million cycles seems reasonable.

Summarizing this, by assigning 10,000 and 10 million cycles to $\varepsilon_{\mathrm{F}}$ and $\varepsilon_{\mathrm{ND}} \mathrm{a}$ theoretical fatigue law can be calculated following these previous two hypotheses. 


\subsection{Test plan}

The variables studied were three: binder type, test temperature and aging. To analyze the influence of these three variables in the fatigue behavior of the mixture using the EBADE test, the following test matrix was designed, table 3 :

Table 3. Variables studied.

\begin{tabular}{|c|c|c|c|}
\hline Mixture & Binder & Test temperature & Conditioning \\
\hline \multirow{18}{*}{$\begin{array}{c}\text { AC16 5\% binder } \\
\text { cont. }\end{array}$} & \multirow{6}{*}{$50 / 70$} & \multirow{2}{*}{$+10^{\circ} \mathrm{C}$} & Unaged \\
\hline & & & Aged \\
\hline & & \multirow{2}{*}{$+3^{\circ} \mathrm{C}$} & Unaged \\
\hline & & & Aged \\
\hline & & \multirow{2}{*}{$-5^{\circ} \mathrm{C}$} & Unaged \\
\hline & & & Aged \\
\hline & \multirow{6}{*}{ BC 35/50 } & \multirow{2}{*}{$+10^{\circ} \mathrm{C}$} & Unaged \\
\hline & & & Aged \\
\hline & & \multirow{2}{*}{$+3^{\circ} \mathrm{C}$} & Unaged \\
\hline & & & Aged \\
\hline & & \multirow{2}{*}{$-5^{\circ} \mathrm{C}$} & Unaged \\
\hline & & & Aged \\
\hline & \multirow{6}{*}{ PMB 45/80-65 } & \multirow{2}{*}{$+10^{\circ} \mathrm{C}$} & Unaged \\
\hline & & & Aged \\
\hline & & \multirow{2}{*}{$+3^{\circ} \mathrm{C}$} & Unaged \\
\hline & & & Aged \\
\hline & & \multirow{2}{*}{$-5^{\circ} \mathrm{C}$} & Unaged \\
\hline & & & Aged \\
\hline
\end{tabular}

For each combination of variables, three specimens were tested, giving a total of 54 samples.

\section{Results}

In this section the results obtained in the strain sweep tests performed on the six mixtures at three different temperatures are discussed. As an example of the data that the EBADE test provides, the results from the conventional mixture without aging are presented in Figure 5. 

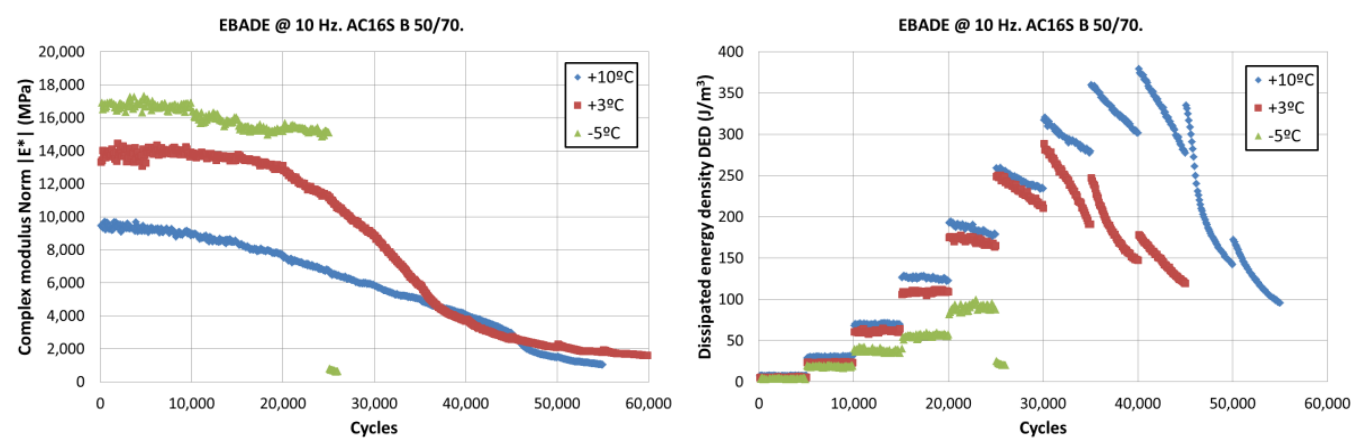

Figure 5. Evolution of the $\left|E^{*}\right|$ and the DED with the number of cycles for the AC16S 50/70 mixture without aging at three temperatures.

The EBADE test provides two main parameters that characterize the behavior of the material under cyclic loading, i.e., the initial complex modulus norm, $\left|\mathrm{E}^{*}\right|_{\mathrm{i}}$, and the failure strain, $\varepsilon_{F}$. The calculation of these two parameters is explained in the EBADE tests section. In addition, during this research a new parameter has been defined, the No-Damage strain, $\varepsilon_{\mathrm{ND}}$. In a strain sweep test, the mixture is exposed to different strain amplitudes in an increasing pattern. At low strain amplitudes there is no change in the $\left|E^{*}\right|$ and DED within each strain step, these parameters only change with the change in strain amplitude every 5,000 cycles, because of the change in the loading rate. Keeping the same frequency and increasing the strain amplitude inevitably leads to a change in the velocity of movement applied to the material, i.e., the loading rate.

However, as the strain amplitude increases, there is a change in the behavior of these two parameters, both experience a loss with the number of cycles during each 5,000 cycle step. The $\varepsilon_{N D}$ is defined as the highest strain amplitude at which the material does not experience a loss in $\left|E^{\star}\right|$ and DED within a strain step. Table 4 shows the numerical values obtained for these three parameters. 
Table 4. Numerical values obtained for $\left|E^{*}\right|_{i}, \varepsilon_{\mathrm{F}}$ and $\varepsilon_{\mathrm{ND}}$ in the EBADE tests.

\begin{tabular}{|c|c|c|c|c|}
\hline Mixture & $\begin{array}{l}\text { Temperature } \\
\left({ }^{\circ} \mathrm{C}\right)\end{array}$ & $\left|E^{*}\right|_{i}(M P a)$ & $\varepsilon_{F}(\mu m / m)$ & $\varepsilon_{\mathrm{ND}}(\mu \mathrm{m} / \mathrm{m})$ \\
\hline \multirow[t]{3}{*}{$50 / 70$} & 10 & 9,368 & 225 & 102 \\
\hline & 3 & 13,343 & 156 & 109 \\
\hline & -5 & 14,016 & 149 & 66 \\
\hline \multirow[t]{3}{*}{ BC 35/50 } & 10 & 11,440 & 225 & 135 \\
\hline & 3 & 12,525 & 175 & 100 \\
\hline & -5 & 14,619 & 150 & 95 \\
\hline \multirow[t]{3}{*}{ PMB } & 10 & 6,639 & 325 & 136 \\
\hline & 3 & 8,707 & 225 & 147 \\
\hline & -5 & 11,267 & 200 & 90 \\
\hline \multirow[t]{3}{*}{ 50/70 Aged } & 10 & 15,021 & 150 & 111 \\
\hline & 3 & 17,845 & 125 & 99 \\
\hline & -5 & 19,005 & 103 & 54 \\
\hline \multirow[t]{3}{*}{ BC 35/50 Aged } & 10 & 13,899 & 172 & 103 \\
\hline & 3 & 16,130 & 150 & 112 \\
\hline & -5 & 19,120 & 112 & 52 \\
\hline \multirow[t]{3}{*}{ PMB Aged } & 10 & 12,500 & 225 & 85 \\
\hline & 3 & 16,511 & 200 & 77 \\
\hline & -5 & 18,399 & 125 & 79 \\
\hline
\end{tabular}

The repeatability of the test depended on the stiffness of the mixture. The failure strain and the No-Damage strain showed similar dispersions. At $10^{\circ} \mathrm{C}$ the coefficient of variation (COV) was $7 \%$ and $15 \%$ on average for the $\left|E^{\star}\right|_{i}$ and the two strain parameters, and at $-5^{\circ} \mathrm{C}$ it increased to $13 \%$ and $17 \%$, respectively.

The fatigue law coefficients and strain amplitudes corresponding to 1 million cycles, $\varepsilon_{6}$, predicted by the model described in sections 2.3 and 2.4 are presented in table 5 .

To better visualize the effect of the binder, temperature and aging on the predicted fatigue behavior, the computer program BISAR 3.0 was employed to calculate the maximum horizontal strain in a low traffic pavement structure. These strain values were then used to predict a number of cycles to failure using the theoretical fatigue laws obtained in the EBADE tests, table 5, using equation 1. The pavement structure used was composed of a subgrade of 50 MPa modulus and 0.4 Poisson ratio, a granular base of $40 \mathrm{~cm}$ with $400 \mathrm{MPa}$ modulus and 0.3 Poisson ratio, and $10 \mathrm{~cm}$ of asphalt mixture with a Poisson ratio of 0.35 and the initial complex modulus obtained for each case in the EBADE tests, Figure 6. 


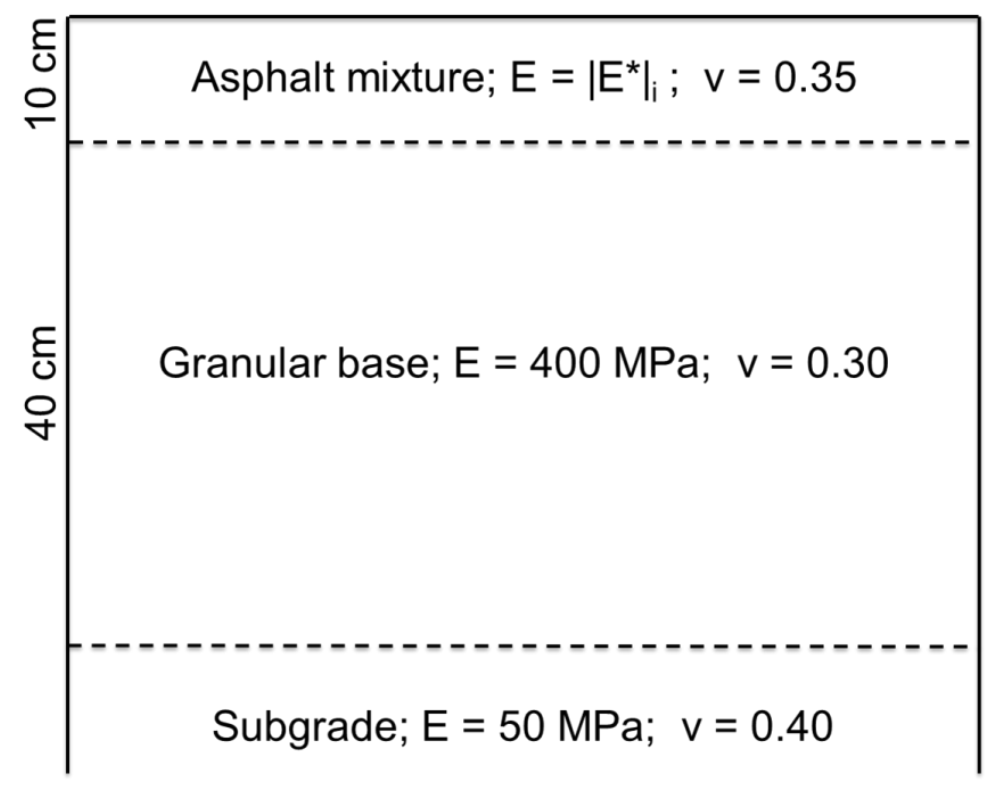

Figure 6. Representation of the layer structure chosen for the BISAR 3.0 calculation.

Table 5. Theoretical fatigue law parameters, according to equation 1 , and predicted strain and number of cycles obtained in BISAR 3.0.

\begin{tabular}{|c|c|c|c|c|c|c|}
\hline Mixture & $\begin{array}{c}\text { Temperature } \\
\left({ }^{\circ} \mathrm{C}\right)\end{array}$ & a & $b$ & $\begin{array}{c}\varepsilon_{6} \\
(\mu \mathrm{m} / \mathrm{mm})\end{array}$ & $\begin{array}{c}\varepsilon_{\text {BISAR }} \\
(\mu \mathrm{m} / \mathrm{mm})\end{array}$ & $\begin{array}{l}\text { Pred. } \\
\text { cycles }\end{array}$ \\
\hline \multirow[t]{3}{*}{$50 / 70$} & 10 & 646.09 & 0.115 & 132 & 136 & 767,041 \\
\hline & 3 & 251.61 & 0.052 & 123 & 118 & $2,108,431$ \\
\hline & -5 & 443.58 & 0.118 & 87 & 116 & 86,409 \\
\hline \multirow[t]{3}{*}{ BC 35/50 } & 10 & 444.61 & 0.074 & 160 & 126 & $>10^{\prime}$ \\
\hline & 3 & 369.05 & 0.081 & 121 & 121 & 952,819 \\
\hline & -5 & 275.79 & 0.066 & 111 & 114 & 650,485 \\
\hline \multirow[t]{3}{*}{ PMB } & 10 & 1038.3 & 0.126 & 182 & 153 & $3,983,358$ \\
\hline & 3 & 396.89 & 0.062 & 169 & 140 & $>10^{7}$ \\
\hline & -5 & 579.98 & 0.116 & 117 & 127 & 485,609 \\
\hline \multirow{3}{*}{$\begin{array}{l}\text { 50/70 } \\
\text { Aged }\end{array}$} & 10 & 224.1 & 0.044 & 122 & 112 & $7,014,492$ \\
\hline & 3 & 170.59 & 0.034 & 107 & 104 & $2,094,996$ \\
\hline & -5 & 243.65 & 0.093 & 67 & 100 & 14,414 \\
\hline \multirow{3}{*}{$\begin{array}{l}\text { BC 35/50 } \\
\text { Aged }\end{array}$} & 10 & 340.76 & 0.074 & 123 & 116 & $2,109,588$ \\
\hline & 3 & 221.44 & 0.042 & 124 & 109 & $>10^{7}$ \\
\hline & -5 & 311.53 & 0.111 & 67 & 100 & 27,922 \\
\hline \multirow{3}{*}{$\begin{array}{l}\text { PMB } \\
\text { Aged }\end{array}$} & 10 & 823.89 & 0.141 & 117 & 121 & 809,834 \\
\hline & 3 & 714.08 & 0.138 & 106 & 107 & 941,121 \\
\hline & -5 & 230.47 & 0.066 & 93 & 102 & 231,128 \\
\hline
\end{tabular}

The theoretical strain values, $\varepsilon_{\text {BISAR }}$, shown in table 5 may only be considered for comparison purposes, since the BISAR 3.0 software considers semi-infinte layers of isotropic and linear elastic materials, which is quite far from the reality of bituminous materials. 
The fluctuations on the predicted number of cycles to failure were expected since they depended on two complementary properties of the mixture, complex modulus and failure strain. When the temperature decreased, stiffness increased and failure strain decreased at different rates. If the stiffness increased at a higher rate than the failure strain decreased the predicted life could increase, because the theoretical strain in the bottom of the asphalt mixture layer was reduced and still was much smaller than the failure strain. However, if the failure strain decreased at a higher rate than the stiffness increased, even though the predicted strain in the bottom of the layer was lower, it could be closer to the failure strain causing a smaller predicted number of cycles.

\subsection{Temperature effect}

As expected, as the temperature decreased the $\left|E^{*}\right|_{i}$ increased. In general, the stiffer the mixture the less the relative increase in modulus with temperature. The three mixtures studied showed an increase of their $\left|E^{*}\right|_{i}$ when the temperature dropped from 10 to $-5^{\circ} \mathrm{C}$, ranging from $30 \%$ to $70 \%$, the PMB mixture had the highest increase and the $\mathrm{BC} 35 / 50$, the lowest.

However, the variation of $\varepsilon_{\mathrm{F}}$ and $\varepsilon_{\mathrm{ND}}$, table 4 , was more interesting, since it provided information on how the stiffening of the mixtures affected their fatigue behavior. Of all the mixtures, the PMB showed the highest $\varepsilon_{\mathrm{F}}$, the $\varepsilon_{\mathrm{ND}}$ remained at similar values at all temperatures. This was reflected in a higher $\varepsilon_{6}$ at all temperatures.

The mixture manufactured with the conventional binder showed the lowest $\varepsilon_{6}$ values at +10 and $-5^{\circ} \mathrm{C}$. At $+3^{\circ} \mathrm{C}$ it showed a slightly higher value than the $\mathrm{BC}$ $35 / 50$ mixture.

Overall, the modification of the binder, through the addition of either crumb rubber or SBS polymer, improved the fatigue behavior at all temperatures. The crumb rubber binder was harder than the conventional binder, table 1, however, their $\left|E^{*}\right|_{i}$ at all temperatures were very similar and its $\varepsilon_{\mathrm{F}}$ and $\varepsilon_{\mathrm{ND}}$ higher or similar, which resulted in better predicted fatigue behavior. The polymer 
modified binder provided a much more ductile mixture with a predicted fatigue behavior better at all temperatures.

\subsection{Aging effect}

The aging procedure increased the $\left|E^{*}\right|_{i}$ of all mixtures and reduced their $\varepsilon_{F}$. However, the effect on the $\varepsilon_{N D}$ depended on the mixtures and the test temperature. The PMB mixture experienced a strong reduction of this parameter at all temperatures, while the BC 35/50 and the 50/70 mixtures showed a reduction at +10 and $-5^{\circ} \mathrm{C}$ and a small increase at $+3^{\circ} \mathrm{C}$.

After aging, the BC 35/50 mixture was the one that showed the better predicted fatigue behavior at +10 and $+3^{\circ} \mathrm{C}$. This is due to the strong influence that the modulus has in the multilayer computation software. In addition, the strong reduction of $\varepsilon_{\mathrm{ND}}$ the PMB mixture suffered decreased the predicted $\varepsilon_{6}$ and cycles to failure. However, at $-5^{\circ} \mathrm{C}$ this mixture obtained the better predicted fatigue parameters.

It is important to mention the great drop in the predicted cycles to failure experienced by the BC 35/50 and the 50/70 mixtures when the temperature changed from +3 to $-5^{\circ} \mathrm{C}$. This is the expected behavior for a very brittle and stiff material, i.e., a small change in strain amplitude can make the material shift from the linear visco-elastic domain to total failure. These results are consistent with other research studies, such as the one performed by Saeidi and Aghayan (2016), that showed that aged mixtures at low temperatures experienced a significant decrease in failure deformation obtained using the SCB test.

\subsection{Aging-Temperature superposition}

Comparing the results from different test temperatures of aged and unaged mixtures, it was noted that the data from the test at $+3^{\circ} \mathrm{C}$ of unaged mixtures were very similar to that of the aged mixtures at $+10^{\circ} \mathrm{C}$. The $\left|\mathrm{E}^{*}\right|_{i}, \varepsilon_{\mathrm{F}}$ and $\varepsilon_{\mathrm{ND}}$ of the $50 / 70$ mixture differed by $12 \%, 4 \%$ and $2 \%$, respectively, and for the BC $35 / 50$ mixture those differences were $10 \%, 2 \%$ and $3 \%$ in the same order. These results showed that the aging procedure applied to these mixtures had the same effect as reducing these mixtures service temperature by $7^{\circ} \mathrm{C}$. Figure 
7 shows the similarities in the evolution of $\left|E^{\star}\right|$ with cycles for the 50/70 mixture unaged at $+3^{\circ} \mathrm{C}$ and aged at $+10^{\circ} \mathrm{C}$.

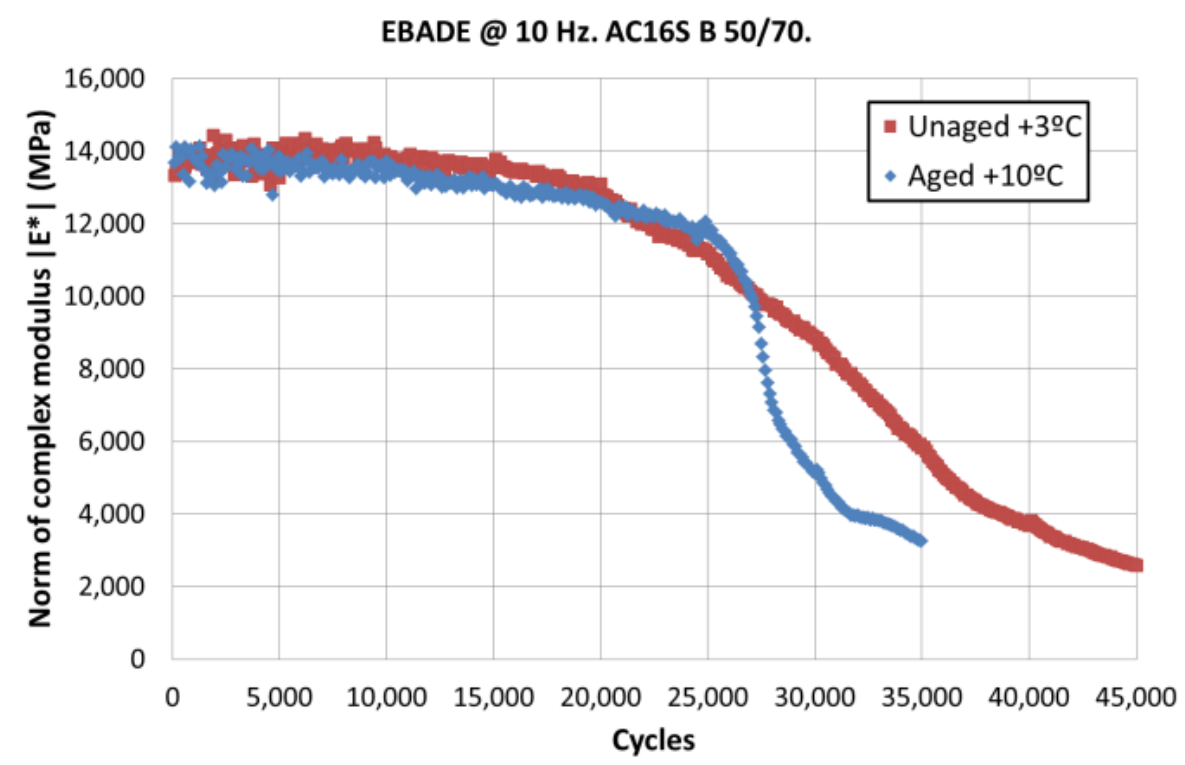

Figure 7. Evolution of $\left|\mathrm{E}^{\star}\right|$ with cycles for the $50 / 70$ mixture unaged at $+3^{\circ} \mathrm{C}$ and aged at $+10^{\circ} \mathrm{C}$.

Results obtained by other researchers in rheological studies of aged and unaged asphalt binders predicted this kind of behavior. Specifically, the work carried out by Padmarekha and Krishnan (2016) recently showed that the temperatures at which the asphalt binder transitions between viscoelastic fluid to viscoelastic solid regimes increased with aging.

The implications of these results extend to the pavement design. Mixtures that are known to have a brittle behavior at low temperatures placed in mild climate areas may become fragile, even at moderate temperatures, because of the aging caused by their exposure to the weather conditions. In other words, the embrittlement mixtures suffer due to aging can be similar to that caused by low temperatures. That may explain the surface cracking observed in bituminous pavements placed in warm climate areas, where low temperature cracking is unlikely. 


\section{Conclusions}

The objective of this research project was to develop a new methodology to estimate the fatigue law of bituminous materials and use it to analyze the influence of the test temperature, the aging and binder type in the fatigue behavior of a continuously graded asphalt mixture. Six different mixtures, fabricated with three different binders, before and after being exposed to an aging procedure were tested at three different temperatures using a strain sweep test called EBADE. From this study the following conclusions were obtained:

- A new methodology was proposed to define the highest strain amplitude at which the mixture properties remain constant with the number of cycles, based on the analysis of results from a strain sweep test.

- Using the Failure strain and the No-Damage strain, an approximation to the fatigue law of the mixture was proposed. The failure strain was associated with failure in a low number of cycles, around 10,000, and the No-Damage strain with failure in the highest practical number of cycles a virtual road would endure in its service life, approximately 10 million.

- The reduction of test temperature reduced the ductility of the mixtures. The mixtures manufactured with modified binders showed better fatigue behavior. The mixture with SBS polymer modified binder retained more ductility at low temperatures, while the mixture with crumb rubber modified binder had the highest stiffness modulus.

- The aging had a similar impact on the mixtures as the reduction of temperature. It produced a significant reduction in their ductility. Again, the mixtures with the modified binders obtained better predicted fatigue parameters, the mixture with SBS polymer modified binder had the better results after aging and at the lowest temperature, which would be the worst-case scenario.

- The aging in the mixture acted like a reduction in the service temperature. This means that aging should be taken into account when designing a mixture to be placed in a given weather climate, i.e., a mixture that should have enough ductility at $+10^{\circ} \mathrm{C}$ can behave like a stiffer mixture at this temperature due to aging. 
- In the design of an asphalt pavement both the temperature and the aging susceptibility of the mixture should be taken into account.

- In all cases, the worst fatigue results were obtained at low temperatures, while the fatigue laws currently employed in designing bituminous mixtures are normally obtained at $+20^{\circ} \mathrm{C}$. The fatigue behavior of bituminous mixtures should be also studied at low temperatures.

\section{Acknowledgements}

Authors would like to acknowledge the company REPSOL for funding this research project under the agreement "Study of the fatigue behavior of bituminous binders and mixtures". 


\section{References}

Al-Azri NA, Jung SH, Lunsford KM, Ferry A, Bullin JA, Davison RR, Glover CJ Binder (2006) Oxidative aging in Texas pavements: Hardening rates, hardening susceptibilities, and impact of pavement depth. Transport Res Rec: J Transport Res Board 1962:12-20.

Anderson DA, Marasteanu MO (1999) Physical hardening of asphalt binders relative to their glass transition temperatures. Transport Res Rec: J Transport Res Board, 1661, pp. 27-34.

Carpenter SH, Ghuzlan KA, Shen S (2003) Fatigue Endurance Limit for Highway and Airport Pavements. Transport Res Rec: J Transport Res Board 1832:131-138.

Chen JS, Huang LS (2000) Developing an aging model to evaluate engineering properties of asphalt paving binders. Mater Struct 33(233):559-565.

Claudy PM, Letoffe JM, Rondelez F, Germanaud L, King G, Planche JP (1992) A new interpretation of time-dependant physical hardening in asphalt based on DSC and Optical Thermoanalysis. In: 204th ACS Meeting Division of Fuel. Chemistry; 1408-26.

De la Roche C, Van de Ven M, Van den Bergh W, Gabet T, Dubois V, Grenell J, Porot L (2009) Development of a laboratory bituminous mixtures aging protocol. Proceedings of the International Conference on Advanced Testing and Characterization of Bituminous Materials 331-345.

Domke CH, Davison RR, Glover CJ (2000) Effect of oxygen pressure on asphalt oxidation kinetics. Industrial and Engineering Chemistry Research 39(3):592-598.

Gonzalez-Torre, I., Calzada-Perez, M.A., Vega-Zamanillo, A., Castro-Fresno, D. (2015) Evaluation of reflective cracking in pavements using a new procedure that combines loads with different frequencies. Constr Build Mater 75:368-374.

Hintz C, Velasquez R, Johnson C, Bahia H (2011) Modification and validation of linear amplitude sweep test for binder fatigue specification. Transport Res Rec: J Transport Res Board 2207:99-106.

Hu, J., Liu, P., Wang, D., Oeser, M., Tan, Y. (2016) Investigation on fatigue damage of asphalt mixture with different air-voids using microstructural analysis. Const. Build Mater 125:936-945.

Johnson C (2010) Estimating asphalt binder fatigue resistance using an accelerated test method. Ph.D. Thesis, Univesity of Wisconsin-Madison. 
Lu X, Isacsson U, Ekblad J. (2003) Influence of polymer modification on low temperature behaviour of bituminous binders and mixtures. Mater Struct 36(264):652-656.

Ma, T., Zhang, Y., Zhang, D., Yan, J., Ye, Q. (2016) Influences of air voids on fatigue life of asphalt mixture based on discrete element method. Constr Build Mater 126:785-799.

Moreno-Navarro, F., Rubio-Gámez, M.C. (2016) A review of fatigue damage in bituminous mixtures: Understanding the phenomenon from a new perspective Constr Build Mater 113:927-938.

Na Chiangmai C (2014) Experimental evaluation of monotonic and cyclic fracture behavior using disk-shaped compact tension test and released energy approach. Ph.D. Thesis, University of Illinois at Urbana-Champaign.

Naskar M, Reddy KS, Chaki TK, Divya MK, Deshpande APvisco (2013) Effect of ageing on different modified bituminous binders: Comparison between RTFOT and radiation ageing. Mater Struct 46(7):1227-1241.

Padmarekha, A., Krishnan, J.M. (2013) Viscoelastic transition of unaged and aged asphalt. J Mater Civ. Eng 25(12):1852-1863.

Park HJ, Eslaminia M, Kim YR (2014) Mechanistic evaluation of cracking in inservice asphalt pavements. Mater Struct 47(8):1339-1358.

Park SW, Kim YR, Schapery RA (1996) A viscoelastic continuum damage model and its application to uniaxial behavior of asphalt concrete. Mech Mater, 2(4):241-255.

Pérez-Jiménez F, Valdés G, Miró R, Martínez A, Botella R (2010) Fénix test: Development of a new test procedure for evaluating cracking resistance in bituminous mixtures. Transport Res Rec: J Transport Res Board 2181:36-43.

Pérez-Jiménez F, Valdés G, Miró R, Botella R, Campana JM (2011) Effect of thermal stresses on fatigue behavior in bituminous mixes. Transport Res Rec: J Transport Res Board 2210: 90-96.

Pérez-Jiménez F, Valdés GA, Botella R, Miró R, Martínez A (2012) Approach to fatigue performance using Fénix test for asphalt mixtures. Constr Build Mater 26(1):372-380.

Pérez-Jiménez FE, Botella R, Martínez A, Miró R (2013). Estimating the fatigue law of asphalt mixtures using a strain sweep test (EBADE test). 5th European Asphalt Technology Association Conference, Braunschweig, Germany. 
Pérez-Jiménez FE, Botella R, Miró R, Martínez AH (2015) Analysis of the thixotropic behavior and the deterioration process of bitumen in fatigue tests. Const Build Mater 101:277-286.

Petersen JC, Branthaver JF, Robertson RE, Harnsberger PM, Duvall JJ, Ensley EK (1993) Effects of physicochemical factors on asphalt oxidation kinetics. Transport Res Rec: J Transport Res Board 1391:1-10.

Planche JP, Claudy PM, Létoffé JM, Martin D (1998) Using thermal analysis methods to better understand asphalt rheology. Thermochimica Acta, 324(12):223-227.

Sabouri M, Kim YR (2014) Development of a failure criterion for asphalt mixtures under different modes of fatigue loading. Transport Res Rec: J Transport Res Board 2447:117-125.

Sadek, H., Masad, E., Al-Khalid, H., Sirin, O. (2016) Probabilistic analysis of fatigue life for asphalt mixtures using the viscoelastic continuum damage approach. Constr Build Mater 126:227-244.

Saeidi, H., Aghayan, I. (2016) Investigating the effects of aging and loading rate on low-temperature cracking resistance of core-based asphalt samples using semi-circular bending test. Constr Build Mater 126: 682-690.

Struik LCE (1978) Physical aging in amorphous polymers and other materials. Amsterdam: Elsevier Scientific Publishing Company.

Tabatabaee H, Velasquez R, Bahia $\mathrm{H}$ (2012) Modeling thermal stress in asphalt mixtures undergoing glass transition and physical hardening. Transport Res Rec: J Transport Res Board 2296:106-114. 